\title{
PELATIHAN TENTANG METODE MENGAJAR LINGKUNGAN BAGI GURU - GURU PAUD DI DESA AMONGENA KECAMATAN LANGOWAN
}

\author{
Olga R. M. Sumual \\ Fakultas Ilmu Pendidikan, UNIMA
}

\begin{abstract}
The success of an educational process in influenced by several factors bleak teachers, students, facilities and so forth. Has the most important role is as teacher whose job as a teacher educator and professionalism is expected. Environmental education is necessary for all citizens from young children to adults in order to be a healthy environment for the residents. Model learning environment in primary education, especially in early childhood is given by integrating environmental education into existing subjects. Environment in early childhood education teaching is a service activity and in accordance with social learning theory contains aspects that learning together. Analysis of the problem can be identified as follows: lack of knowledge about teaching. Environmental education for teachers - early childhood teachers in the village Amongena District Langowan, there are teachers - teachers who have not been able to integrate environmental education into existing subjects, Based on the training concluded that the implementation of early childhood learning methods in the execution environment is integrated into all existing programs in other words an integrated environmental education in accordance theme / sub theme using existing learning model are: picture and picture. Based on the training concluded that the implementation of teaching methods in early childhood environment is the planning, implementation, observation, and reflection. It is the integration of the environment into the theme of early childhood teaching. With the training of teachers - teachers early childhood in District Langowan then their positive response both from head school and teachers teachers, participants' interest is quite high at the show with seriousness and sincerity of the participants in the training, participants have to understand the methods of teaching environment in early childhood.
\end{abstract}

Keywords: Environmental education, PAUD teacher.

\section{PENDAHULUAN}

Keberhasilan suatu proses pendidikan dipengaruhi oleh beberapa factor seperti guru, siswa, fasilitas dan sebagainya. Yang memiliki peranan yang paling penting adalah guru yang tugasnya sebagai pendidik dan profesionalitas seorang guru sangat diharapkan.

Kompetensi merupakan kemampuan yang dapat ditampilkan oleh setiap lulusan dari proses pendidikan dan lulusan mestinya memiliki kemampuan untuk memenuhi tuntutan tujuan pendidikan di PAUD khususnya metode mengajar lingkungan. Ini berarti mampu mentransfer pengetahuan kepada peserta didik tetapi juga mampu mengadakanlmenggunakan suatu pendekatan yang kreatif dan inovatif yang melibatkan peserta didik dalam proses belajar mengajar.

Pendidikan lingkungan diperlukan bagi semua warga dari yang masih kecil sampai dewasa agar bisa menjadi lingkungan yang sehat bagi penghuninya. Pendidikan lingkungan merupakan pendidikan perilaku yang dilakukan sejak dini di kalangan keluarga dan masyarakat dan secara formal dilakukan di sekolah mulai dari pendidikan dasar sampai pendidikan tinggi. 
Model pembelajaran lingkungan pada pendidikan dasar yaitu khususnya di PAUD diberikan dengan cara mengintegrasikan pendidikan lingkungan dalam mata pelajaran yang sudah ada. Mulyati (2005) dari hasil penelitian melalui pembelajaran secara kolaboratif, secara bersama menentukan permasalahan yang dihadapi dan cara pemecahan masalah yang disepakati membentuk nilai-nilai positif yang diterima lebih mudah bagi siswa.

Berdasarkan hasil observasi awal terdapat indicator yang menunjukkan bahwa guru-guru PAUD di Amongena yaitu PAUD di Amongena masih banyak yang belum dapat mengintegrasikan pendidikan lingkungan dalam semua mata pelajaran yang sudah ada. Hal ini terjadi karena kurangnya informasi serta kurangnya sosialisasi bagi para guru.

Menyadari kenyataan tersebut, maka sudah selayaknya UNIMA sebagai Perguruan tinggi yang memiliki tenaga tenaga professional memberi perhatian terhadap permasalahan diatas dalam rangka melaksanakan Tri Darma Perguruan Tinggi yaitu darma pengabdian pada masyarakat. Hal ini dapat dilakukan antara lain melalui pengadaan pelatihan bagi guruguru dalam hal ini pelatiha metode mengajar lingkungan, demi menunjang profesibaik dibidang belajar mengajar maupun di bidang penelitian dalam rangka promosi kenaikan pangkat dan jabatan sebagai kompetensi profesionalisme guru.
Berdasarkan analisis situasi diatas, maka masalah dapat diidentifikasikan sebagai berikut: Kurangnya pengetahuan tentang pengajaran pendidikan lingkungan PAUD di Desa Amongena Kecamatan Langowan, Kurangnya ketrampilan dalam metode pengajaran lingkungan di PAUD.

Berdasarkan hasil pengamatan di lapangan maka dirumuskan masalah sebagai berikut: Bagaimana cara memotivasi guru-guru tentang pendidikan lingkungan di PAUD desa Amongena agar memahami tentang metode mengajar pendidikan lingkungan. Bagaimana agar guru-guru dapat mengintegrasikan pendidikan lingkungan dalam lingkungan yang sudah ada.

Agar guru-guru di PAUD Amongena Mengetahui/memahami tentang pendidikan lingkungan di sekolah Agar guru-guru dapat mengintegrasikan pendidikan lingkungan dalam mata pelajaran yang sudah ada Manfaat kegiatan pengabdian pada masyarakat ini adalah seebagai berikut : Meningkatkan profesionalisme guru-guru di PAUD Amongena, Meningkatkan pre stasi akademik guru-guru PAUD di Amongena Kecamatan Langowan dalam melaksanakan tugas belajar mengajar.

\section{KAJIAN LITERATUR}

Berdasarkan kajian literatur yang ada yaitu : pengertian lingkungan, kebijakan dalam pendidikan lingkungan, metode dalam pengajaran lingkungan, model pembelajaran lingkungan, penyediaan alat 
peraga, materi lingkungan yang terintegrasi dalam mata pelajaran.

\section{Pengertian Lingkungan Hidup}

Lingkungan menurut Kamus Besar Bahasa Indonesia 'Poerwadarminta, 1976) adalah berasal dari kata lingkungan yaitu sekeliling atau sekitar. Lingkungan adalah bulatan yang melingkupi atau melingkar sekalian yang terlingkupi di suatu daerah disekitamya. Menurut ensiklopedia umum (1977) lingkungan adalah alam sekitar termasuk orang-orang dalam hidup pergaulan yang mempengaruhi manusia sebagai anggota masyarakat dalam kehidupan dan kebudayaannya.

Dalam ensiklopedia Indonesia (1983) lingkungan adalah segala sesuatu yang ada di luar suatu organisme meliputi: 1. lingkungan mati (abiotik) yaitu lingkungan di luar suatu organisme yang terdiri atas benda factor alarn yang tidak hidup seperti bahan kimia, suhu, cahaya, gravitasi, atmosfir dan lainnya. 2. Lingkungan hidup (biotic) yaitu lingkungan di luar organisme yang terdiri atas organisme hidup seperti tumbuhan, hewan dan manusia.

Lingkungan Hidup menurut UU RI No 4 tahun 1982 tentang ketentuan pokok pengelolaan lingkungan hidup dan UU RI No 23 tahun 1997 tentang pengelolaan lingkungan hidup dikatakan bahwa lingkungan hidup adalah kesatuan ruang dengan daya, keadaan mahluk hidup lainnya. Banyak ahli yang mengemukakan pengertian tentang lingkungan dan lingkungan hidup pada dasamya sama.

\section{Pendidikan Lingkungan dan \\ Perkembangan}

Pendidikan lingkungan sebenamya sudac lama dikenal. Pada peri ode 1960 1980 sudah ada usaha mengenalkan lingkungan dalam pendidikan yang dikenal sebagai pendekatan lingkungan. Namun pada masa itu lingkungan lebih dikenalkan melalui pendidikan sebagai media. Gagasan perlunya pendidikan lingkungan sebagai pendidikan dalam lingkungan dan pendidikan untuk lingkungan disekolah dimulai sekitar 40 tahun yang lalu.

Pendidikan lingkungan merupakan pendidikan perilaku yang dilakukan sejak dini di kalangan keluarga dan masyarakat dan secara formal dilakukan di sekolah mulai dari pendidikan dasar sampai pendidikan tinggi. Di pendidikan dasar dan menengah pendidikan lingkungan ditujukan agar siswa memahami lingkungan dan ikut bertanggung jawab dan berbuat untuk menciptakan lingkungan sehat bagi kehidupan. Untuk pendidikan tinggi diharapkan juga agar mahasiswa memiliki kemampuan mengambil keputusan yang terkait dengan masalah lingkungan.

Pendidikan lingkungan dilakukan dengan cara menghadapkan siswa pada isu lingkungan dan melakukan pengamatan pada kondisi yang sebenaynya melalui data primer atau data sekunder. Dari pengamatan data tersebut diharapkan siswa 
dapat mengidentifikasikan dampak sosial, ekonomi dan lingkungan baik secara local, nasional dan global juga menentukan bagaimana tindakan yang harus dilakukan.

Untuk mencapai tujuan pendidikan lingkungan ada beberapa konsep dasar yang perlu dikembangkan. Pertama yaitu prinsip dasar ekologi yang menyangkut struktur ekologi, energi dalam ekosistim, siklus materi dalam kehidupan, kependudukan, evaluasi dan ekologi. Kedua tentang manusia dalam lingkungan menyangkut energi dan aktivitas manusia, mineral dan sumber air, makanan dan kemiskinan. Ketiga tentang dampak aktivitas manusia terhadap kesehatan yang menyangkut polusi udara, dampak dan penanganannya serta berbagai cara untuk memperoleh air bersih, penggunaan tanah dan polusi tanah, sampah dalam ekosfer, kesehatan dan lingkungan, produk sintetik dan polusi, perubahan musim dan bencana alam.

Selanjutnya nilai dasar yang perlu dikembangkan adalah mengangkut etika yang menekankan bahwa tidak seorangpun boleh menggunakan lingkungan seenaknya dimanapun mereka berada. Estetika dan budaya menyangkut perlindungan terhadap lingkungan yang menunjukkan identitas budaya suatu bangsa dan konsep lingkungan yang memiliki aspek ekonomi.

\section{Kebijakan dalam Pendidikan Lingkungan}

Lingkungan sekolah perlu dijadikan pusat sumber belajar. Dalam pelaksanaan28 nya apalagi pada pendidikan dasar dan menengah pendidikan lingkungan tidak harus menjadi mata pelajaran baru yang berdiri sendiri tetapi terintegrasi dalam semua program yang ada di sekolah khususnya bagi pendikan dasar dan menengah (Hungerforld, 1990). Karena faktanya pendidikan lingkungan tak hanya mengembangkan pemahaman lingkungan tetapi merupakan pendidikan yang menekankan pada pengembangan perilaku dan tindakan positif terhadap lingkungan.

Berdasarkan ciri pengembangan perilaku dalam pendidikan maka perilaku terhadap lingkungan ini berkembang secara bertahap, memerlukan latihan, contoh dan monitoring secara terus menerus agar nilainilai lingkungan dapat menjadi bagian dalam lingkungan anak.

Ada tiga hal yang perlu mendapat perhatian dan memerlukan kebijakan sekolah (Ligorio, 2006) yaitu : Sekolah sebagai basis pengembangan pendidikan lingkungan, Kebijakan tentang sumber belajar yang dapat digunakan, Pengintegrasian lingkungan dalam kurikulum, program dan perencanaan. Model Pembelajaran lingkungan.

\section{Pendidikan Anak Usia Dini (PAUD)}

PAUD adalah pendidikan yang ditujukan bagi anak usia 3-6 tahun (PP no 27/1990 pasal 6). Undang-undang no 20 tahun 2003 pasal 28 bahwa memberikan perhatian lebih besar pada jenjang pendidikan ini, bahwa pendidikan perlu 
dilakukan sejak lahir sampai dengan usia enam tahun yang disebut pendidikan anak usia dini. Pendidikan anak pada usia dini sangat memegang peranan penting karena anak memiliki karakteristik perkembangan dan kemampuan tersendiri. Beberapa ahli pendidikan dan psikologi memandang mas a anak merupakan masa yang sangat penting yang perlu mendapat penanganan sedini mungkin. Proses belajar pada anakanak dilakukan dalam nuansa bermain karena dunia anak dunia bennain.

Bermain adalah dunia anak sekaligus sarana belajar anak. Memberikan kesempatan bermain kepada anak berarti memberikan kesempatan pada anak untuk belajar. Memberikan kesempatan pada anak untuk belajar dengan cara-cara yang bersifat bennain berarti telah berusaha membuat pengalaman belajar yang dirasakan dan dipersepsi dengan secara alami oleh anak sehingga menjadi bermakna baginya (Solehudin \& Hatimah, 2007).

\section{Metode Pembelajaran Lingkungan di PAUD}

Pendidikan lingkungan
pendidikan dasar seperti di
pelaksanaannya terintegrasi dalam semua
program yang ada di sekolah (Hungerfold,
1990). Dengan kata lain pendidikan
lingkungan terintegrasi sesuai dengan
temalsub tema dengan memakai model
pembelajaran yang ada. Sebagai contoh
model pembelajaran picture and picture
yang sesuai dengan temalsub tema yang

diberikan guru di PAUD. Model pembelajaran ini merupakan salah satu bentuk media model pembelajaran kooperatif. Menurut Hamdani (2010) pembelajaran picture and picture adalah metode belajar yang menggunakan gambar dan dipasangkan atau diurutkan menjadi urutan logis.

Dalam kamus besar Bahasa Indonesia (Depdikbud, 2001:329) gambar adalah tiruan barang, binatang, tumbuhan dan sebagainya bila dihubungkan dengan lingkungan yaitu gambar seperti pohonpohon, gunung, binatang dan lain-lain. Gambar-gambar itu sebagai alat peraga haruslah dibuat semenarik agar menarik perhatian siswa sehingga proses pembelajaran menjadi aktif, inovatif, kreatif dan menyenangkan karena tertarik dengan gambar gambar yang ada. Media gambar menurut Riyanto (1990) merupakan salah satu jenis bahasa yang memungkinkan terjadinya komunikasi yang diekspresikan lewat tanda dan symbol.

Memang banyak model pembelajaran di PAUD. Dari ciri-ciri model pembelajaran menurut Kardi dan War Nglimun (2013: 8) yaitu:

- Rasional teoritik logis yang disusun oleh para pencipta atau para penyebarannya;

- Landasan pemikiran tentang apa dan bagaimana peserta didik belajar;

- Tingkah laku peserta didik;

- Lingkungan belajar yang diperlukan;

- Prinsip-prinsip penggunaan model pembelajaran. 
Secara umum prinsip penggunaan model pembelajaran adalah bahwa tidak semua model pembelajaran cocok digunakan untuk mencapai semua tujuan dan keadaan seperti model pembelajaran picture and picture. Menurut Istarani kelebihannya adalah materi yang diajarkan lebih terarah siswa cepat menangkap dapat meeningkatkan daya nalar anak, dapat meningkatkan tanggung jawab siswa sebab guru menanyakan alasan siswa mengurutkan gambar. Pembelajaran lebih berkesan sebab siswa dapat mengamati langsung gambar yang telah dipersiapkan oleh guru. Sedangkan kekurangan dari model pembelajaran picture and picture adalah sulit menentukan gambar gambar yang bagus, sulit menemukan gambargambar yang sesuai dengan daya nalar atau kempetensi yang dimiliki siswa, baik guru dan siswa kurang terbiasa sebagai bahan utama dalam membahas suatu materi.

\section{METODE PENGABDIAN}

Metode pelatihan yang digunakan dalam pelatihan ini adalah pelarajan lingkungan bagi guru - guru PAUD di Amongena adalah metode ceramah, Tanya jawab, pemberian tugas, demonstrasi dan diskusi.

\section{HASIL DAN PEMBAHASAN}

Pelaksanaan pelatihan bagi guruguru PAUD di Kecamatan Langowan adalah sebagai berikut : Adanya respons positifbaik 30 dari kepala sekolah dan guru-guru, Animo peserta cukup tinggi ditunjukkan dengan keseriusan dan kesungguhan peserta dalam mengikuti pelatihan dan Peserta sudah memahami metode mengajar lingkungan di PAUD. Pelaksanaan pengajaran lingkungan di PAUD serta model pembelajaran dideskripsikan berikut ini.

\section{Perencanaan}

1. Guru menyiapkan/menyusun rencana kegiatan dengan tema/sub tema pendidikan lingkungan termasuk nya yaitu mengenai model pembelajaran picture and picture.

2. Menyiapkan Media Pembelajaran. Guru menyediakan alat peraga sebagai media pembelajaran dan media yang digunakan yaitu gambar-gambar yang disesuaikan dengan materi contoh gambar dan makanan serta binatang peliharaan.

3. Menyiapkan pedoman observasi. Berupa lembar penilaian untuk guru yang mengajar dan dinilai oleh guru kelas sebagai ternan sejawat.

4. Menyiapkan lembar kerja siswa.

5. Menyiapkan lembar penilaian berupa lembar observas kegiatan yang dilakukan siswa.

\section{Tahap Pelaksanaan Tindakan}

\section{Pendidikan Lingkungan di PAUD}

Pelaksanaan di sini meliputi seluruh proses kegiatan pernbelajaran dimulai dengan kegiatan awal, inti dan kegiatan 
penutup yang disusun dalam rencana kegiatan Harian sebagai beikut:

- Kegiatan awal 30 menit. Guru menyambut anak-anak mengajak anak memberi dan membalas saam kepada guru juga ternan-teman. Guru mengarahkan anak untuk berbaris dan menyanyi di lapangan dilanjutkan dengan pengecekan kehadiran dan menanyakan kabar juga kesiapan anakanak. Pada awal kegiatan ini guru mengajar anak-anak Tanya jawab / bercakap tentang gambar misalnya gambar tong sampah diceritakan bahwa sampah itu harus dimasukkan dalam tong sampah. Bila mbar binatang guru bercerita tentang binatang, manfaat, suara binatang berkaki empat. Bertanya kepada anak siapa yang pemah melihat binatang berkaki emapat (sapi, domba, kucing, kelinci, anjing), apa makanannnya dan manfaatnya. Anakanak akan menjawab pertanyaan guru. Jawaban anak itu sebagai langkah awal untuk mengetahui kemampuan anak terhadap materi yang disampaikan.

- Kegiatan inti 60 menit. Pada kegiatan ini sebagai contoh guru melaksanakan pembelajaran dengan menggunakan metode picture and picture (gambar dan gambar) dengan langkah-langkah:

$\checkmark$ Guru menyampaikan kompetensi yang ingin dicapai. Dasar guru untuk menyampaikan temasub tema misalnya binatang berkaki empat yang hidup di darat atau tentang kebersihan lingkungan atau dengan gambar sekolah yang bersih atau gambar pohon-pohon dll, Guru memberikan materi lingkungan diintegrasikan pada mata pelajaran atau sesuai dengan temalsub tema terdapat Tanya jawab

$\checkmark$ Guru menciptakan suasana yang menyenangkan di dalam kelas dengan mengajar anak bernyanyi sambil bermain. Sambil bemyanyi guru menyebutkan suara binatang sehingga murid menebaknya, Guru menyediakan gambar-gambar yang digunakan.

$\checkmark$ Guru memperlihatkan gambar dan meminta anak menyebutkan gambar tersebut.

$\checkmark$ Guru mengajarkan anak-anak mengurutkan memasang gambar tersebut.

$\checkmark$ Guru memberikan pertanyaan mengenai alasan anak dalam menentukan urutan gambar setelah itu guru mengajak anak menentukan urutan gambar yang benar.

$\checkmark$ Istirahat/makan Guru mengarhkan cara makan yang baik. Guru mengajarkan anak berbaris secara teratur, mencuci tangan supaya bersih. Setelah itu masuk dalam kelas ambil bekal masing-masing dari loker selanjutnya guru minta pada anak-anak untuk duduk dan berdoa sebelum makan. Ketika sedang makan tidak boleh bercerita. 
Setelah makan anak-anak akan bermain guru menasihatkan untuk berhati-hati tidak boleh mengganggu teman

Kegiatan Penutup ada kegiatan menyanyi beberapa lagu anak, Tanya jawab tentang kegiatan pembelajaran yang telah dilakukan kemudian memperingatkan kepada anak untuk tidak lupa memberikan salam sesampai di rumah, ganti seragam dengan pakaian rumah, buat latihan, jangan lupa makan dan tidur siang. Kemudian anak-anak menyanyi, mengucapkan doan dan memberi salam.

\section{Tahap Observasi/Pengamatan}

Pada tahap observasi II pemgamatan untuk siklus I, dilaksanakan ketika proses pembelajaran berlangsung. Guru mengamati kemampuan anak dalam mengurutkan / memasangkan sesuai dengan pasangan yang sesuai dengan kartu yang dipegang anak.

Pengamatan terhadap kemampuan guru dalam menerapkan model picture and picture guru hams menguasainya. Dalam pengamatan mengenai kemampuan anak untuk mengenal binatang pada siklus pertama bila ada anak yang kurag dalam pencapaiannya tujuan pembelajaran selesai yang diharapkan sehingga proses pembelajaran dilanjutkan pada siklus selanjutnya.

\section{Refleksi}

Pada siklus I ini dapat dilihat bahwa hasil pencapaian perkembangan yang diperoleh sesuai setelah mengikuti proses pembelajaran.

\section{KESIMPULAN}

Kegiatan pengabdian pada masyarakat dalam bentuk pelatihan metode mengajar lingkungan vagi guru-gum PAUD di desa Amongena Kecamatan Langowan telah dilaksanakan dengan baik. Pelaksanaan pelatihan ini telah mencapai tujuan yang diharapkan karena semua peserta dapat memahami tentang metode mengajar lingkungan hidup di PAUD.

\section{KEPUSTAKAAN}

Nasution, S. 1987, Berbagai pendekatan proses belajar dan mengajar, Jakarta, Bina Aksara.

Kementrian Lingkungan Hidup, 1997, Agenda 21 Indonesia, Strategi Nasional untuk pembangunanjangka berkelajutan, Jakarta Pusat Studi Lingkungan.

Mulyati, 2005, Pengembangan Pendidikan Lingkungan Terpadu, Lokakarya Pendidikan Lingkungan Jawa Barat.

Adobe, 2003, Implementation of Enviromental Education tersedia pada http.coc.pdf

Brans, J. AS Wood, D, 1993. Enviromental in the School, Washington DC peace Corps. Unesco, 1989, Intergovernmental Conference on Enviromental, Paris.

Mulyati A, 2005, pengembangan Pendidikan Lingkungan Terpadu, Lokakarya Pendidikan Lingkungan , Jawa Barat. 
Hungerforld, 1990, Changing Leamer behavior Through Enviromental Education. The Journal of Enviromental Educational, 21.
Solehudin \& hatimah, 2007, Pendidikan Anak usia dini, Bandung, Pegagogik Press.

Nglimin, 2013, Strategi Model dan pembelajaran , Jogyakarta, Asmajaya, Prasindo. 
Jurnal ABDIMAS, Vol. 10, No. 01, Juni 2017 ISSN: 1979-0953 